\title{
ALFABETIZAÇÃO E LETRAMENTO: PERCURSO HISTÓRICO E MÉTODOS
}

\author{
Edilaine Monteiro De Santana ${ }^{1}$
}

\section{Resumo:}

O presente artigo tem como temática a alfabetização/letramento, seus métodos e o percurso histórico brasileiro da Educação Infantil no Brasil. Para tal, realizou-se uma revisão bibliográfica de textos disponíveis no portal Google Acadêmico. Iniciou-se com leituras superficiais e posteriormente leituras mais profundas em que foram selecionados livros, capítulos de livros, artigos científicos publicados em revistas e eventos. Após a seleção foi realizada a análise dos dados com base em itens e subitens das ideias principais dos autores pesquisados.

Palavras-chave: Educação Infantil. Alfabetização. Letramento. Métodos.

\begin{abstract}
:
This article has as its theme the literacy/literacy, its methods and the Brazilian historical path of Early Childhood Education in Brazil. To this end, a bibliographic review of texts available on the Google Academic portal was carried out. It began with superficial readings and later deeper readings in which books, book chapters, scientific articles published in magazines and events were selected. After selection, data analysis was performed based on items and sub-items of the main ideas of the authors surveyed.
\end{abstract}

Keywords: Early Childhood Education. Literacy. Literacy. Methods.

\section{INTRODUÇÃO}

A Educação Infantil é a modalidade de ensino voltada para crianças de 0 a 6 anos de idade. É ofertada em centros de educação infantil e têm como objetivos é promover aos estudantes o desenvolvimento de diversos aspectos como: motor, físico, cognitivo, social, emocional, além de incitar a exploração, novas descobertas e a experimentação (na prática).

\footnotetext{
${ }^{1}$ Mestranda em Ciências da Educação pela Universidad Del Sol - UNADES, Assunção/PY. E-mail: edilainemanzoni@yahoo.com.br
} 
O atendimento a crianças em creches e pré-escolas é um direito assegurado pela Constituição Federal de 1988. Entretanto, foi com a aprovação da Lei de Diretrizes e Bases da Educação Nacional (LDB), em 1996, que a Educação Infantil foi reconhecida como a primeira etapa da Educação Básica, sendo um complemento ao Estatuto da Criança e do Adolescente (ECA), de 1990.

O Referencial Curricular Nacional para a Educação Infantil (RCNEI), de 1998, é um documento lançado em três volumes com o objetivo de auxiliar na realização de trabalho educativo diário junto às crianças. Nele são estabelecidos objetivos, conteúdos e orientações didáticas para os profissionais que atuam diretamente com crianças de zero a seis anos.

Com a legalidade que exigia uma Educação Infantil pautada em determinados princípios, as discussões em torno do ensino- aprendizagem desses pequenos estudantes foram intensificadas. O terceiro volume do RCNEI (1998) tem como temática "Movimento, Música, Artes Visuais, Linguagem Oral e Escrita, Natureza e Sociedade e Matemática". Nota-se que não bastava mais apenas o assistencialismo, era necessário que se iniciasse as crianças a lerem e escreverem.

Advindos deste contexto histórico e de movimentos de alfabetização europeus, no Brasil, iniciou-se profundas discussões sobre a alfabetização e o letramento. O que se discutia é que não bastava ensinar apenas a decifrar os códigos linguísticos, era necessário que se entendesse seu uso e suas colocações em vários contextos de forma que permitisse o exercício pleno da cidadania.

E foi devido a essas discussões que se estabeleceu a questão norteadora deste estudo: Quais as distinções entre alfabetização/letramento, quais os métodos mais utilizados e em qual contexto histórico estão inseridos?

Tem-se como objetivo geral compreender o processo de alfabetização e letramento. Como objetivos específicos apresentam-se: a) compreender o surgimento da Educação Infantil; b) distinguir alfabetização e letramento; c) elencar e distinguir os métodos de aquisição da leitura e escrita mais utilizados no decorrer dos tempos.

\section{PROCEDIMENTOS METODOLÓGICOS}

A presente pesquisa trata-se de uma revisão bibliográfica. É uma investigação elaborada a partir de material já publicado, Tem como objetivo "[...] colocar o 
pesquisador em contato direto com todo material já escrito sobre o assunto da pesquisa (PRODANOV; FREITAS, 2013, p. 54).

Para esta pesquisa, fizemos uso do Portal Google Acadêmico para fazer o levantamento da literatura que foi utilizada. $O$ processo envolveu primeiramente leituras superficiais para a seleção dos textos e depois uma leitura mais profunda para a escolha daqueles que realmente comporiam nossa pesquisa.

Esta investigação fez uso principalmente de: livros, capítulos de livros, artigos científicos publicados em revistas e eventos. Prodanov e Freitas (2013) também sugerem uma pesquisa de cunho bibliográfico pautada nesses tipos de texto como eficiente.

A análise dos dados dos textos selecionados foi realizada com base em um roteiro dos pontos principais dos documentos. Foram sendo estabelecidos itens e subitens das ideias dos atores e posteriormente selecionados quais conceitos e opiniões seriam tragos para este artigo.

\section{REFERENCIAL TEÓRICO}

O que se sabe é que nem sempre as crianças tiveram a oportunidade de estudar. Houve um tempo na história em que elas eram tratadas como "pequenos adultos" na maneira de se comportar e se vestir, entretanto, a elas não era dado o direito à educação (ARIÈS,1978).

Esse contexto social começou a mudar depois da Revolução Industrial. As fábricas começaram a contratar mulheres para trabalharem - o que não era muito comum para a época, e com isso, veio a necessidade de ter lugares adequados para que as crianças ficassem enquanto a mãe estava trabalhando (KUHLMANN JR., 2002).

O autor supracitado conta que as primeiras "instituições escolares" foram fundadas no "quintal das fábricas". Como necessitaria manter essas crianças ocupadas iniciou-se o processo de alfabetização delas, já que estavam ali prontas para aprender.

Entretanto, o que se pode entender pela história do surgimento da Educação Infantil é que se deu por movimentos assistencialistas. Nota-se pelas palavras de Neves (2014) que estavam focados em promover assistencialismo social às pessoas de baixa renda ou que viviam à margem da sociedade: 
Os primeiros movimentos voltados para o cuidado da criança foram em 1874, na qual as Câmaras Municipais do Brasil passaram a destinar uma ajudar financeira para as crianças negras, místicas ou brancas que eram rejeitadas, tinha que apresentar periodicamente às crianças as autoridades. Um tempo depois foi criada pela a Igreja Católica as Rodas dos Expostos, ou dos rejeitados essa instituição era de cunho filantrópico da Santa Casa de Misericórdia, e foram se espalhando pelo país no século XVIII (NEVES, 2014, p. 9).

A alfabetização passou por vários estágios, tanto no fora do Brasil quanto dentro dele, tais mudanças coram acompanhadas por transformações políticas, sociais e econômicas. Araújo (1996) divide a história da alfabetização em três grandes períodos: a) na Antiguidade e Idade Média: com a predominância do método da soletração; b) criação de novos métodos sintéticos e analíticos (Séculos XVI e XVIII): seria uma reação contra o método da soletração; c) Psicogênese da língua escrita: refutação da associação dos sinais gráficos da escrita aos sons da fala.

$\mathrm{Na}$ atualidade não se entende mais a alfabetização segundo esses três períodos. Devido ao grande índice de fracasso de alfabetização, atualmente, a alfabetização é vista pela ótica da sociolinguística e na psicolinguística. Mendonça (2010) explica como essas ciências interferiram na maneira de alfabetizar:

\footnotetext{
Sugere um trabalho que partindo da realidade do aluno desenvolva e valorize sua oralidade por meio do diálogo, que trabalhe conteúdos específicos da alfabetização e utilize estratégias adequadas às hipóteses dos níveis descritos na psicogênese da língua escrita. Recomenda, também, a leitura de textos de qualidade, de diferentes gêneros, interpretação e produção textual, estratégias indispensáveis ao desenvolvimento de aspectos específicos da alfabetização aliados a sua função social (MENDONÇA, 2010, p. 24).
}

Morrou (1969) explica que na primeira fase do surgimento da alfabetização utilizava-se como método a soletração ou método alfabético. As crianças tinhas que decorar o nome das letras, sua ordem e só então começarem a grafá-las e associar o som e a forma escrita. Só então eram inseridas as famílias silábicas e as sílabas mais complexas. Era um processo lento, bastante complexo em que o estudante levaria ao menos 4 anos para aprender.

Já na Idade Média, segundo Araújo (1996), utilizava-se a mesma sistemática (letra, sílaba, palavra, texto). Entretanto, os textos tinham um cunho religioso e eram todos escritos em latim. Para que aprendessem eram oferecidos às crianças ainda em 
tenra idade por meio de vários materiais: alfabetos de couro, tecido, madeira e até mesmo em ouro.

De acordo com Mendonça (2010, p. 25), foi por volta de 1719 que Vallange criou "método fônico" com as "figuras simbólicas". Nele se tinha o objetivo de mostrar "[...] palavras acentuando o som que se queria representar. Entretanto, o exagero na pronúncia do som das consoantes isoladas levou tal método ao fracasso". Mesmo tendo fracassado nesse período, ainda hoje, há defensores desse método.

Posteriormente foi criado na França o método silábico. Nele o foco se dava da união entre consoantes e vogais para formar sílabas. Nessa metodologia de alfabetização a sílaba é apresentada pronta, sem se explicitar a articulação das consoantes com as vogais. Esses três métodos (soletração, fônico e silábico) são intitulados de métodos sintéticos, conforme vemos no Quadro 1 que segue:

\section{Quadro 1 - Métodos Sintéticos}

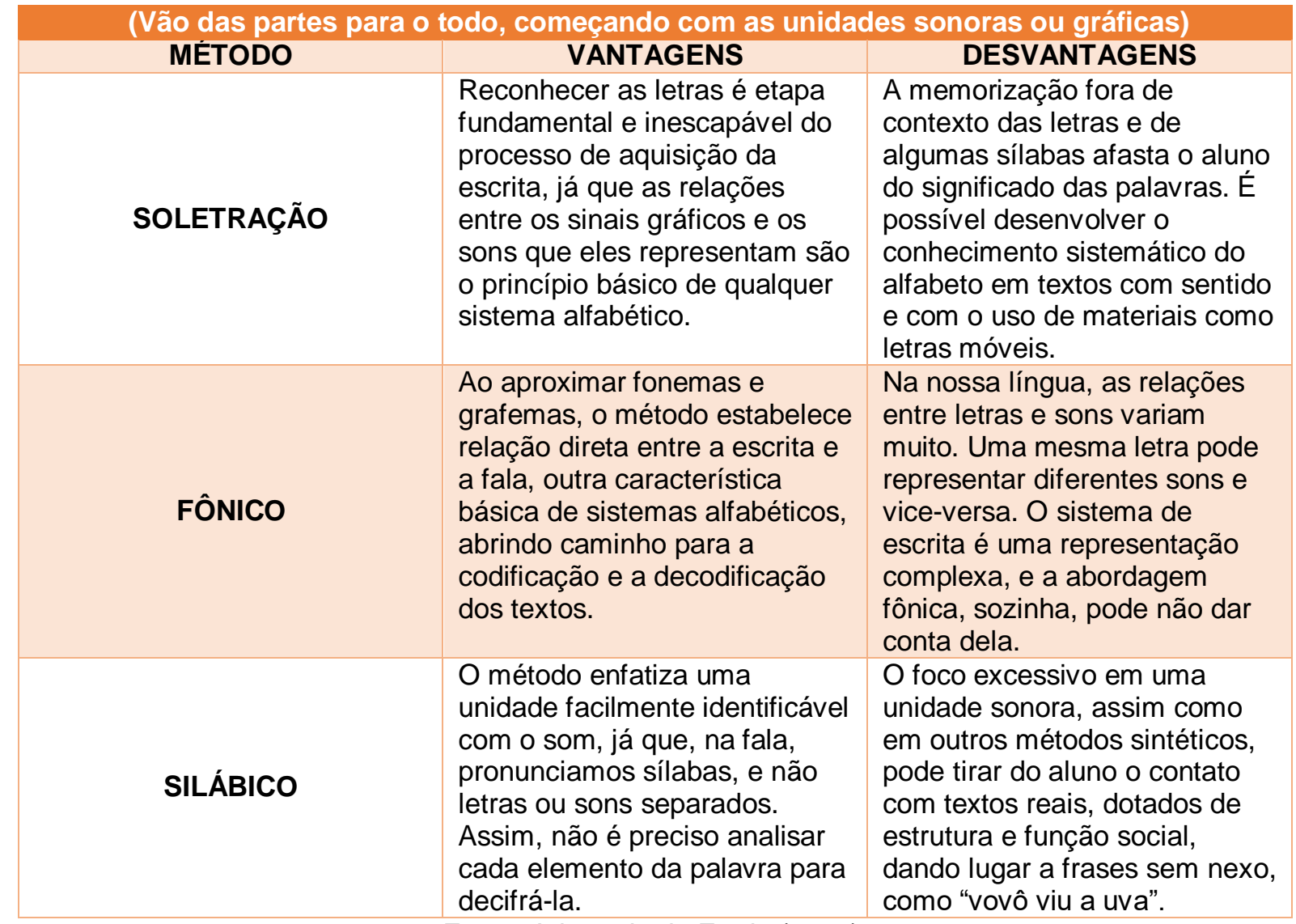

Fonte: Adaptado de Frade (2018).

Com o passar dos anos esses métodos sintéticos não foram capazes de alfabetizar com qualidade e outros foram surgindo. Os métodos da palavração, sentenciação e o global são de origem analítica porque partem de uma unidade maior 
que possui significado, para então fazer sua análise em unidades menores. Devido a isso são bastante focados em textos e interpretação inicialmente.

Cagliari (1999) explica que o método da palavração se trata do uso de uma palavra de forma que seja reconhecida graficamente sem a necessidade de decompôla em sílabas ou letras. Nesse caso, a criança seria capaz de "ler" a palavra "CocaCola" sem al menos conhecer as letras "C" e "L" e sua família.

No caso do método de sentenciação também se trabalha com uma unidade maior, entretanto não apenas com uma palavra, mas com uma frase completa. Nesse caso, a criança é capaz de reconhecer o sentido de uma frase inteira e depois o professor vai fragmentando-a em palavras e sílabas (CAGLIARI, 1999).

O autor supracitado explica ainda sobre o método global. Essa metodologia parte de um texto, trabalhado por certo tempo, no qual o aluno memoriza e entende o sentido geral do que é "lido". Posteriormente se analisam as sentenças (sentenciação) e se identificam as palavras (palavração), comparando as suas composições silábicas (silabação). Vejamos suas vantagens e desvantagens no Quadro 2:

Quadro 2 - Métodos Analíticos

\begin{tabular}{|c|c|c|}
\hline METODO & VANTAGENS & DESVANTAGENS \\
\hline PALAVRAÇÃO & $\begin{array}{l}\text { É um meio-termo entre as } \\
\text { práticas sintéticas e as } \\
\text { analíticas, pois permite } \\
\text { trabalhar em unidades } \\
\text { menores, sem dissociá-las do } \\
\text { significado. O aluno aprende } \\
\text { estratégias de leitura } \\
\text { inteligente e associa a leitura } \\
\text { com prazer e informação. }\end{array}$ & $\begin{array}{l}\text { Focar só no reconhecimento } \\
\text { gráfico das palavras pode } \\
\text { prejudicar a análise das } \\
\text { sílabas, letras e grafemas, } \\
\text { afetando o reconhecimento de } \\
\text { palavras novas. Isso costuma } \\
\text { ser amenizado pelo uso de } \\
\text { palavras estáveis, como o } \\
\text { nome próprio. }\end{array}$ \\
\hline SENTENCIAÇÃO & $\begin{array}{l}\text { A exemplo do método de } \\
\text { palavração, a sentenciação } \\
\text { permite que os alunos se } \\
\text { relacionem com o significado } \\
\text { dos textos e aprendam, desde } \\
\text { o início da alfabetização, a } \\
\text { utilizar estratégias de leitura } \\
\text { inteligente. }\end{array}$ & $\begin{array}{l}\text { O ensino por sentenciação } \\
\text { pode acarretar problemas } \\
\text { semelhantes aos encontrados } \\
\text { na palavração, como a } \\
\text { dificuldade de decodificar } \\
\text { textos novos por falta de uma } \\
\text { análise mais detida nas } \\
\text { unidades que compõem a base } \\
\text { do sistema de escrita. }\end{array}$ \\
\hline GLOBAL & $\begin{array}{l}\text { Com práticas semelhantes às } \\
\text { adotadas pela moderna } \\
\text { alfabetização de linha } \\
\text { construtivista, o método } \\
\text { mantém o foco no sentido dos } \\
\text { textos e proporciona, desde o } \\
\text { início da aprendizagem, o } \\
\text { contato com o texto. }\end{array}$ & $\begin{array}{l}\text { O trabalho sistemático com as } \\
\text { unidades menores, que são } \\
\text { parte da estrutura básica da } \\
\text { língua escrita, pode ficar } \\
\text { enfraquecido. Além disso, o } \\
\text { uso só de textos para fins } \\
\text { escolares não é positivo: a } \\
\text { criança precisa conviver com } \\
\text { textos reais. }\end{array}$ \\
\hline
\end{tabular}

Fonte: Adaptado de Frade (2018). 
$\mathrm{Na}$ atualidade, o que os estudiosos defendem é que não há um único método de alfabetização eficiente, por si só. Entretanto, é preciso que os alfabetizadores conheçam as teorias que envolvam o ato de ensinar as crianças a lerem e escreverem para então serem capazes de escolher qual seria a melhor maneira, para aquele grupo ou para uma determinada pessoa.

Pensando nisso, Mendonça (2010) criou um quadro contendo uma sinopse das fases de cada método. Com isso, podemos ver as cinco fases de cada método citado anteriormente. Vejamos no Quadro 3:

Quadro 3 - Sinopse das fases dos métodos

\begin{tabular}{|c|c|c|c|c|c|c|}
\hline FASES & \multicolumn{6}{|c|}{ MÉTODOS } \\
\hline Métodos & Soletração & Fônico & Silábico & Palavração & Sentenciação & $\begin{array}{c}\text { Contos e da } \\
\text { experiência } \\
\text { infantil }\end{array}$ \\
\hline $1^{a}$. fase & $\begin{array}{l}\text { Alfabeto: } \\
\text { Letra, nome } \\
\text { e forma }\end{array}$ & $\begin{array}{l}\text { Letras: } \\
\text { som e forma }\end{array}$ & $\begin{array}{c}\text { Letras: } \\
\text { consoantes } \\
\text { e vogais }\end{array}$ & Palavras & Sentenças & $\begin{array}{l}\text { Conto } \\
\text { ou texto }\end{array}$ \\
\hline $2^{a}$. fase & Sílaba & Sílabas & Sílabas & Sílabas & Palavras & Sentenças \\
\hline $3^{\text {a }}$. fase & Palavras & Palavras & Palavras & Letras & Sílabas & Palavras \\
\hline $4^{a}$. fase & Sentenças & Sentenças & Sentenças & Sentenças & Letras & Sílabas \\
\hline $5^{\text {a }}$. fase & $\begin{array}{l}\text { Contos } \\
\text { ou textos }\end{array}$ & $\begin{array}{l}\text { Contos } \\
\text { ou textos }\end{array}$ & $\begin{array}{l}\text { Contos } \\
\text { ou textos }\end{array}$ & $\begin{array}{l}\text { Contos } \\
\text { ou textos }\end{array}$ & $\begin{array}{l}\text { Contos } \\
\text { ou textos }\end{array}$ & Letras \\
\hline
\end{tabular}

Fonte: Mendonça (2010, p. 28).

As Cartilhas de alfabetização foram responsáveis pela perduração dos métodos tradicionais de alfabetizar no Brasil. As mais conhecidas foram: Cartilha Sodré, Caminho Suave, Cartilha da Infância e dominaram por décadas essa modalidade de ensino brasileiro (CAGLIARI, 1996).

Segundo o autor supracitado, nas cartilhas, a leitura ocorria "[...] através de exercícios de decifração e de identificação de palavras, por meio dos quais os alunos aprendiam as relações entre as letras e sons, seguindo a ortografia da época (CAGLIARI, 1996, p. 31). Esse pequeno "livro" enfatizava o alfabeto, as palavras, as 
sílabas geradoras e textos que deveriam ser decorados. Todos apresentados em uma ordem de dificuldade crescente.

Outro método que não poderíamos deixar de citar aqui, e que não está nos quadros anteriores é o chamado "Método Paulo Freire". Ele ficou mundialmente conhecido por ter criado uma metodologia diferente para alfabetizar adultos. Tal método parte do diálogo e conscientização, da análise e síntese de uma palavra cujo significado o aprendiz já conheça.

Sobre o Método Paulo Freire, Mendonça (2010) defende que ele não foi devidamente valorizado no Brasi:

O Método Paulo Freire foi pouco divulgado e estudado, no Brasil; quando usado pelo Mobral, foi descaracterizado, porque teve seus passos da "codificação" e "descodificação" excluídos do processo de alfabetização, sendo transformado em mero método das cartilhas, impedindo os alfabetizadores e alfabetizandos de fazer a "leitura de mundo", que transforma a consciência ingênua em consciência crítica. Como este tema merece aprofundamento será estudado no texto: A eficiência do Método Sociolinguístico: uma nova proposta de Alfabetização (MENDONÇA, 2010, 35).

Bordignon e Paim (2017), em sua pesquisa sobre a alfabetização no Brasil, levantaram os conceitos e práticas pedagógicas relacionadas à alfabetização e ao letramento brasileiro. As autoras relatam que há pouca literatura sobre essa temática e que essa escassez fica ainda mais evidente quando se trata do "letramento", por ser um conceito relativamente recente.

Com a incorporação do construtivismo nas práticas pedagógicas de todo o Brasil foi que o letramento surgiu. Apesar de estar relacionado ao ensino e aprendizagem a alfabetização e o letramento têm conceitos distintos.

Enquanto a alfabetização é o processo de aquisição do sistema de escrita
alfabético, ou seja, da aprendizagem da leitura e da escrita, de forma mais
específica, o letramento refere-se às capacidades e às habilidades do sujeito
em utilizar essas aprendizagens nos diferentes contextos sociais das práticas
de leitura e escrita (SOARES, 2001 apud BORDIGNON; PAIM, 2017, p. 57).

O surgimento do letramento se deu ao perceber que não bastava ser alfabetizado, ou seja, saber ler e escrever. Era preciso que essa leitura e essa escrita levasse o sujeito às suas práticas cotidianas no exercício da cidadania. Entendemos que para gerar melhores propostas de ensino e de aprendizagem, no âmbito da alfabetização e do letramento, seja necessário a compreensão de que esses dois 
conceitos têm sido compreendidos e teorizados por autores distintos de diversas formas.

O termo letramento é considerado bastante atual no campo da educação brasileira. Bordignon e Paim (2017) explicam sobre o seu surgimento na literatura da seguinte maneira:

[...] aparentemente, o termo foi utilizado pela primeira vez no Brasil, em 1986, pela pesquisadora Mary Kato no livro de sua autoria intitulado No mundo da escrita: uma perspectiva psicolinguística. Como parte de título de livro, o termo apareceu em 1995 nos livros Os significados do letramento, organizado por Angela Kleiman, e Alfabetização e letramento, de Leda V. Tfouni (BORDIGNON; PAIM, 2017, p. 58).

Em resumo, a alfabetização é uma etapa do ensino brasileiro enquanto que o letramento é aquilo que se espera atingir nos alunos dessa modalidade de ensino. Entendemos que seja imprescindível o conhecimento e distinção entre esses dois conceitos, por parte por professores, para que se possa escolher a melhor metodologia para se trabalhar com as crianças.

Soares (2001, p. 39) em sua obra sobre letramento pontua que "[...] alfabetizado é aquele indivíduo que sabe ler e escrever", e letrado é o sujeito "[...] que vive em estado de letramento [...] aquele que usa socialmente a leitura e a escrita, pratica a leitura e a escrita, responde adequadamente às demandas sociais de leitura e de escrita".

Tal ideia corrobora com o que Freire $(1987$, p. 7) aponta para o conceito de alfabetização numa perspectiva de letramento. $O$ autor afirma que "[...] aprender a ler, a escrever, alfabetizar-se é, antes de mais nada, aprender a ler o mundo, compreender o seu contexto, não numa manipulação mecânica de palavras, mas numa relação dinâmica que vincula linguagem e realidade".

Compreende-se, portanto, que seja necessária a compreensão do ato de alfabetizar com suas especificidades enquanto processo de aquisição da escrita alfabética. Entretanto, assim como Freire (1987) pontua, é preciso que esse processo seja desenvolvido a partir de práticas de letramento. Ou seja, todas as ações propostas pelo docente alfabetizador devem estar relacionadas às experiências cotidianas dos sujeitos. 


\section{CONSIDERAÇÕES FINAIS}

A presente pesquisa bibliográfica permitiu um levantamento histórico e metodológico da alfabetização e do letramento no Brasil e no mundo. Com ela foi possível observar a importância da escrita, da linguagem e dos processos de ensino para a humanidade. Haja vista que tais processos acompanham as mudanças políticas, sociais, econômicas e, ao mesmo tempo, promovem transformações em vários âmbitos na sociedade

Nota-se que a alfabetização brasileira vem sendo marcada por grandes desafios, avanços e entraves. Nem sempre sua oferta se deu a todos, ainda mais aos mais desafortunados, entretanto o domínio da escrita passou a ser uma necessidade a ser suprida diante do contexto socioeconômico vigente.

Os métodos de alfabetização iniciaram com metodologias sintéticas (soletração, fônico e silábico) que partem das partes para o todo. Posteriormente com a inserção da psicologia escolar começou-se a questioná-los oportunizando o surgimento dos métodos analíticos (palavração, sentenciação, global) que partem do todo para as partes.

Há de se entender que não há uma única maneira de se alfabetizar uma criança. É preciso conhecer todos os métodos e analisar suas especificidades e adequá-las ao contexto vigente. Além disso, entende-se que não basta apenas decodificar símbolos, ou ler e escrever, é preciso que o estudante seja capaz de compreender a funcionalidade da língua e da linguagem nos mais diversos contextos sociais, de forma que se possa exercer plenamente sua cidadania.

\section{REFERÊNCIAS}

ARIÈS, P. História social da criança e da família. 1. ed. Rio de Janeiro: Zahar, 1978.

ARAÚJO, M. C. de C. S. Perspectiva histórica da alfabetização. Viçosa: Universidade Federal de Viçosa, 1996.

BORDIGNON, L. H. C.; PAIM, M. M. W. Alfabetização no brasil: um pouco de história. Educação em Debate, Fortaleza, ano 39, № 74 - jul./dez. 2017.

BRASIL. Constituição da República Federativa do Brasil. São Paulo: Imprensa Oficial do Estado, 1988. 
Estatuto da Criança e do Adolescente. Lei no 8.069/90, de 13 de julho de 1990. São Paulo: CBIA-SP, 1991.

. Lei de Diretrizes e Bases da Educação Nacional. Lei nº 9.394/96, de 20 de dezembro de 1996.

Referencial Curricular Nacional para a Educação Infantil. Brasília: MEC/SEF, 1998.

CAGLIARI, L. C. Alfabetizando sem o bá-bé-bi-bó-bu. São Paulo: Scipione, 1999.

NEVES, G. A educação infantil e o seu contexto histórico. 2014. Disponível em: https://meuartigo.brasilescola.uol.com.br/pedagogia/a-educacao-infantil-seucontexto-historico.htm. Acesso em: 14 jun. 2018

FRADE, I. Formas clássicas de ensinar a língua escrita e o que as pesquisas afirmam sobre elas. 2018.2 Disponível ceale.fae.ufmg.br/app/webroot/glossarioceale. Acesso em: 04 jun. 2018.

FREIRE, P. A importância do ato de ler: em três artigos que se completam. 20. ed. São Paulo: Cortez, 1987.

GIL, A. C. Como elaborar projetos de pesquisa. 4. ed. São Paulo: Atlas, 2008.

KUHLMANN JR, M. A Circulação das ideias sobre a educação das crianças: Brasil início do século XX. In: FREITAS, M. C.; KUHLMANN JR., M. (Orgs). Os intelectuais na história da infância. São Paulo: Cortez, 2002. p. 459-501.

MENDONÇA, O. S. Percurso Histórico dos Métodos de Alfabetização. Faculdade de Ciências e Tecnologia, 2010. Disponível em: https://acervodigital.unesp.br/bitstream/123456789/40137/1/01d16t02.pdf. Acesso em: 03 jun. 2018.

MARROU, H. História da educação na antiguidade. São Paulo: Herder, 1969.

PRODANOV, C. C.; FREITAS, E. C. de. Metodologia do trabalho científico: métodos e técnicas da pesquisa e do trabalho acadêmico. 2. ed. Novo Hamburgo: Feevale, 2013.

SOARES, M. Letramento: um tema em três gêneros. 2. ed. Belo Horizonte: Autêntica, 2001. 